\title{
EL CINE EN LA LITERATURA: LA INFLUENCIA CINEMATOGRÁFICA EN $L A$ NOCHE DE LA USINA DE EDUARDO SACHERI
}

\author{
Claudia Caño Rivera \\ (Universidad de Sevilla) \\ claudia_ca_ri@hotmail.es
}

\begin{abstract}
RESUMEN: Este artículo se centra en analizar la influencia del cine en la novela La noche de la Usina del escritor y guionista argentino Eduardo Sacheri. Tras exponer brevemente los mayores aportes en cuanto a las relaciones entre literatura y cine, comenzamos nuestro análisis mediante la comparación del prólogo de la novela y el tráiler cinematográfico, pues ambos funcionan como paratextos. Seguidamente, se analiza cómo es posible detectar la influencia de la escritura del guion en la construcción narrativa de la novela. Por último, estudiamos la presencia de los géneros cinematográficos del thriller y el western en la obra, pues ambos ayudan a construir el lenguaje de los personajes y el desarrollo de la trama.
\end{abstract}

PALABRAS CLAVE: narrativa contemporánea, guion, tráiler, Eduardo Sacheri, géneros cinematográficos.

\section{CINEMA INTO LITERATURE: THE FILM INFLUENCE IN EDUARDO SACHERI'S LA NOCHE DE LA USINA}

ABSTRACT: This paper focuses on analyzing the influence of film in the novel $L a$ noche de la Usina by the Argentinian writer and scriptwriter Eduardo Sacheri. After a brief exposition of the most important contributions to Film and Literature Theory, our analysis begins by comparing the novel's prologue to the cinematographic trailer, since both communicative instances function as paratexts. Consequently, we analyze how the influence of script writing can be observed in the narrative construction of the novel. Finally, we study how both the thriller and the western as cinematographic genres are present in the novel, helping to build the character's language and the development of the story.

KEYWORDS: Contemporary Narrative, script, trailer, Eduardo Sacheri, Cinematographic Genres.

\section{INTRODUCCIÓN}

Las relaciones entre literatura y cine han sido objeto de reflexión durante todo el siglo XX, y con especial relevancia a partir de la segunda mitad. En los comienzos del cine era común que se llevasen a la gran pantalla argumentos sacados de novelas. A menudo, los propios guionistas eran escritores, por lo que la interrelación entre ambos medios narrativos fue creciendo, de modo que cada vez se hizo más difícil discernir de qué manera influyeron mutuamente el uno en el otro. Si bien la literatura aportó temas y argumentos, el cine trajo a la historia escrita nuevas formas de narrar, así como una mayor predominancia de los detalles visuales. Sin embargo, con frecuencia el estudio de las relaciones entre cine y literatura se ha limitado al campo de la adaptación — pues en esta práctica se vuelve indudable la interrelación entre ambas artes - dejando de lado 
interesantes temas como son la posible influencia del cine en la literatura más allá del précinema.

En este artículo nos proponemos analizar de qué manera se muestra en la novela La noche de la Usina, del escritor argentino Eduardo Sacheri, esa estrecha relación entre lo audiovisual y lo escrito. Con este objetivo, nos gustaría proponer una comparación entre el prólogo de La noche de la Usina y la función y estructura del tráiler cinematográfico, pues ambos funcionan en calidad de paratextos (siguiendo la terminología de Genette). El tráiler cinematográfico ha sido el gran olvidado en los estudios de cine, aunque su existencia es complementaria a la del film, por lo que nuestro estudio pretende rescatar y explicar en la medida de lo posible sus características más notables y de qué manera estas pueden plasmarse en un texto literario. Por otra parte, estudiaremos también la posible influencia de la técnica de escritura del guion en la novela. Además de destacar que el propio autor ha trabajado en diversas ocasiones como guionista en las adaptaciones de sus libros y que en varias declaraciones ha explicado las relaciones entre la palabra y la imagen en su propia obra, es interesante analizar de qué forma prevalece la importancia de lo visual en la novela a la hora de narrar. Sin embargo, la estrecha relación de Sacheri con el cine no solo abarca su faceta como guionista, sino que sus propias novelas estarán plagadas de referencias cinematográficas, y sus personajes serán, al igual que el propio autor, unos verdaderos fanáticos de las películas. Siguiendo esta línea, analizaremos cómo La noche de la Usina puede ser considerada una revisión de dos grandes géneros cinematográficos, el western y el thriller, no solo en la construcción de la trama y los espacios en los que se desarrolla la narración, sino también en la de los propios personajes, los cuales aprenderán a ver la realidad a través de claves cinematográficas conforme avance su historia.

\section{CONTEXTUALIZACIÓN DEL AUTOR Y LA OBRA}

Nacido en argentina en 1967, Eduardo Sacheri —escritor, guionista y profesor de historia - saltó a la fama internacionalmente tras la concesión del Óscar a la mejor película extranjera a El secreto de sus ojos (Juan José Campanella, 2009), de la que fue coguionista y que está basada en su novela La pregunta de sus ojos (2005). La noche de la Usina, Premio Alfaguara 2016, es su penúltima novela. Ambientada en la Argentina de 2001, narra la historia de un grupo de vecinos del pequeño pueblo de O'Connor. Con el objetivo de comprar el almacén de grano La Metódica, Perlassi y su hijo Rodrigo, Fontana, Belaúnde, Medina, los hermanos López, Lorgio y el hijo de este, Hernán, ponen en común todos sus ahorros, y deciden, convencidos por el gerente, ingresarlos en el banco. Sin embargo, sufrirán una estafa a manos del empresario Fortunato Manzi y Alvarado, el gerente bancario, quien, sabiendo que el corralito ${ }^{1}$ era inminente, concede a Manzi un préstamo exprés por el total del dinero que acababan de ingresar. Cuando los protagonistas descubren, tras el estallido de la burbuja, que han sido engañados, pondrán en marcha un plan para entrar en la cámara fuerte de Manzi y recuperar el dinero que les fue robado.

1 Conjunto de medidas financieras adoptadas por el gobierno de Fernando de la Rúa en Argentina a partir del 3 de diciembre de 2001 y que se prolongarían hasta el 2 de diciembre de 2002. Se impidió la libre disposición de dinero en efectivo por parte de los ciudadanos para evitar una fuga masiva de capitales y se instauró un límite de retirada de 250 pesos o dólares estadounidenses por semana. 
Sacheri comenzó su carrera escribiendo relatos donde el fútbol era el tema principal, y que fueron leídos en Radio Continental por el locutor Alejandro Apo (Villa, 2013) y recogidos en Esperándolo a Tito, su primer libro. Un año más tarde publicaría Te conozco Mendizábal, que, según relata el propio Sacheri, sería el detonante definitivo que establecería su contacto con el cine a través del director Juan José Campanella, junto al que escribiría el guion para la adaptación de su novela La pregunta de sus ojos. Esta colaboración, sin embargo, no quedaría ahí, ya que en 2010 se embarcaron en el proyecto de realizar una película de animación, Metegol, en la que Sacheri, de nuevo, ejercería de guionista con el objetivo de adaptar el relato «Memorias de un wing derecho», del escritor argentino Roberto Fontanarrosa (Blanc, 2010). Sin embargo, la estrecha relación de Sacheri con el cine no solo abarca su faceta como guionista, sino que sus propias novelas estarán plagadas de referencias cinematográficas, y sus personajes serán, al igual que el propio autor, unos verdaderos entusiastas del séptimo arte. La noche de la Usina se une a este imaginario literario, pero también a su trayectoria como guionista, pues el propio Sacheri es el encargado de redactar, junto a Sebastián Borensztein, el guion original para la adaptación de su novela, estrenada el 15 de agosto de 2019 en cines argentinos bajo el título La Odisea de los Giles.

\section{LA LITERATURA Y EL CINE}

Desde su nacimiento, el cine se ha servido de la literatura a modo de fuente de inspiración, convirtiendo grandes clásicos como La Cenicienta, Blancanieves o el repertorio shakesperiano en obras adaptadas a la gran pantalla. La propia Viaje a la luna, emblemática obra del gran Georges Meliès, estaría basada en De la tierra a la luna (1865), de Julio Verne, y Los primeros hombres en la luna (1901), de H. G. Wells. En España también se hizo usual encontrar adaptaciones de grandes clásicos a la gran pantalla, entre ellos la versión de El Lazarillo de Tormes de Florián Rey (1925), o, en el plano de la dramaturgia, el Don Juan que en 1910 estrenaron Ricardo de Baños y Alberto Marro. Por otra parte, también es notable el uso de obras más contemporáneas y que obtuvieron un gran éxito en taquilla, como pueden ser las versiones de Mala raza (1912) y A fuerza de arrastrarse (1924), ambas piezas originales del dramaturgo José Echegaray. La relación entre cine y literatura, estrecha desde un principio, se fue definiendo a lo largo del tiempo, dando lugar a una simbiosis entre ambas artes: no solo el cine utilizó los recursos y las tramas de la literatura, sino que esta, a su vez, fue paulatinamente incorporando formas y contenidos propios de la cultura cinematográfica.

Luis Miguel Fernández Fernández (1993) realiza un recorrido por las opiniones que los primeros teóricos de la Literatura Comparada mantenían sobre la posibilidad de incluir el cine en sus estudios. Durante los años sesenta, la tendencia generalizada era la de excluir el cine de los estudios comparatistas, pues se consideraba que el protagonista de la investigación tenía que ser la literatura en sí misma (Wellek, 1968), aunque algunos teóricos admitían que, en ocasiones, el contexto artístico podía ayudar a esclarecer el significado de una obra (Pichois y Rousseau, 1969). En los setenta, las artes mixtas (ópera, historias gráficas, cine...) eran consideradas con cada vez mayor frecuencia como un campo legítimo de la Literatura Comparada (Weisstein, 1975), aunque todavía existía cierta confusión al respecto, por lo que se orientaba la comparación de las artes hacia el campo más amplio de la ciencia cultural (Smichtt-von Mühlenfels, 1984; Schmeling, 1984). A partir de los ochenta encontramos ya propuestas 
más interesantes, como la de Álvaro Manuel Machado, que reconoce el comparatismo literario como un modelo de investigación centrado en estudiar las relaciones de la literatura con otros fenómenos culturales, entre los que incluye el cine, poniendo un especial énfasis en las adaptaciones literarias (en Fernández Fernández, 1993: 39). Añade Luis Miguel Fernández que, aunque el objetivo primario de la Literatura Comparada sea el de alcanzar una poética comparada universal, en muchos casos sería imposible entender las relaciones literarias que se establecen entre distintos movimientos sin recurrir al cine, de manera que no podríamos «[...] estudiar las analogías o recepción de las vanguardias y el surrealismo franceses en la España del primer tercio del siglo veinte [sic] prescindiendo de la visión que en ambos se tiene del cine como ruptura del universo literario anterior» (Fernández Fernández, 1993: 42). Dentro del panorama español nos gustaría destacar las aportaciones que realizan al estudio de las relaciones entre la literatura y el cine los teóricos Jorge Urrutia, Carmen Peña-Ardid y José Luis Sánchez Noriega.

Para Urrutia, «El cine influye de manera clara y evidente en el pensamiento del hombre contemporáneo» (1975: 9), afirmación de la que podríamos extraer que, inevitablemente, influirá también en la concepción literaria contemporánea. A pesar de esto, Urrutia (1984) plantea la pregunta de hasta qué punto podríamos hablar de un préstamo de «estructuras cinematográficas» en la narrativa y no de influencia de otras obras del mismo género, e, incluso, si se confirmase ese préstamo, qué certezas tendríamos de que no sea más que una devolución de técnicas que el cine ya tomó prestadas anteriormente de la literatura. Para este autor, las relaciones entre cine y literatura han de ser establecidas desde el campo de la comparación de los enunciados e, incluso, a través del estudio de los sistemas, pues se trataría en ambos casos de actividades comunicativas (Urrutia, 1999).

Carmen Peña-Ardid (1999) apuesta también por un método comparativo y admite que, formalmente, podría haber rasgos comunes en la materia de expresión de cine y literatura, no en cuanto a similitud entre imagen y palabra, sino en lo relacionado al sistema rítmico, la temporalidad y la secuencialidad. Rechaza, además, la dicotomía de influencia-rechazo del medio cinematográfico, argumentando que, si bien la novela autorreflexiva de los 60 era muy consciente de su naturaleza literaria, está lejos de ser ese «paraíso incontaminado» de la influencia del cine, pues será imposible que se alejen de la cultura audiovisual que ya desde los 50 había comenzado a instaurarse (PeñaArdid, 1996).

En este contexto, es interesante considerar la aportación de Sánchez Noriega, quien apoya la existencia de novelas filmables: «relatos concebidos para la pantalla en cuyo proceso de escritura se ha tenido en cuenta una posible adaptación al cine» (2000: 37). Como ejemplo de este fenómeno ofrecerá la novela negra americana, que recibe una influencia directa del cine, y, más concretamente, hablará del caso de El tercer hombre, película inspirada en un relato de Graham Greene. Según argumenta Noriega a propósito del texto literario que dio lugar a esta película, «podemos hablar de novela cinematográfica como el relato de un escritor que da una forma literaria a un argumento sabiendo que esa forma es provisional y condicionada a su puesta en escena fílmica, que será la forma definitiva» (2000: 168). Si bien La noche de la Usina no concuerda con la definición propuesta por Noriega, pues se trata, ante todo, de una novela, y esta es su forma primera y definitiva, podría haber cierta relación con el término de novela filmable, ya que de un modo consciente o inconsciente el escritor puede haber trasladado sus conocimientos cinematográficos previos al relato, integrando características en la novela que facilitarían su posterior adaptación cinematográfica. 
Como ya vimos anteriormente, Sacheri mantiene una íntima relación con el cine, no solo personal (pues, como sus personajes, es un gran aficionado a las películas) sino también laboral, por lo que, como explicaba Peña-Ardid (1996), acabará siendo inevitable que toda esa cultura audiovisual se vuelque en su historia.

\section{Prólogo y tráiler: propuesta comparativa}

La novela comienza con un prólogo titulado «Un hombre sentado en un banco viejo», donde se narra brevemente la historia de Arístides Lombardero, el maestro de ceremonias del Circo de los Hermanos Lombardero. En este breve inciso, alejado de la historia principal, se narra la excitación que recorría el pueblo cuando llegaba el circo y, en particular, el cuentacuentos. A pesar de no estar relacionado con la trama que recorre la novela, el prólogo sirve como presentación de la historia que se va a contar, no solo como breve disposición de los hechos sino como reseña de los procedimientos narrativos que se utilizarán más adelante. Por lo tanto, podríamos argumentar que la función tanto del prólogo de la novela como del tráiler cinematográfico es presentar el producto al lector/espectador. En este sentido, Maurizio Regosa (2003) los ha identificado a ambos como paratextos, siguiendo la terminología de Gérard Genette:

[...] un cierto número de producciones, verbales o no, como el nombre del autor, un título, un prefacio, ilustraciones, que no sabemos si debemos considerarlas o no como pertenecientes al texto, pero que en todo caso lo rodean y lo prolongan precisamente por presentarlo, en el sentido habitual de la palabra, pero también en su sentido más fuerte: por darle presencia, por asegurar su existencia en el mundo, su «recepción» y su consumación, bajo la forma (al menos en nuestro tiempo) de un libro (2001: 7).

Ambas construcciones coinciden en su función de presentar el producto narrativo al mundo; sin embargo, el texto de La noche de la Usina va más allá, pues a través del personaje de Lombardero arrojará luz sobre los procesos creativos de la novela. Lombardero es un narrador, pero no se puede decir que sea un cuentacuentos a la vieja usanza, ya que «sus narraciones empezaban por cualquier sitio y parecía encontrar placer en confundir al auditorio» (Sacheri, 2016: 12). ${ }^{2}$ Estas narraciones, que generan la total atención de su público mimetizan, para Carolina Miranda, la propia narrativa de la novela: «Thus, the novel imitates the non-temporality of Lombardero's narrative style, subverting chronological order in favour of presenting events "not as they really occurred but as they were perceived and interpreted by the people"» (2018: 110-111). El procedimiento narrativo que Lombardero utiliza para contar sus historias mimetizará, a su vez, el del cine, contando historias que empiezan in media res («Y después habría empezado a contar, pero no por el principio, sino por el lugar adonde lo indujera su impulso, el azar o el escándalo de la concurrencia», 13) y que juegan a superponer tiempos; narraciones con un aparentemente confuso hilo narrativo (es decir, yuxtaponiendo escenarios y personajes) donde el público era el encargado de encontrar el significado y el sentido, o lo que es lo mismo, se veía obligado a recrear en sus mentes el montaje de la narración. Sin embargo, Lombardero no se limitaba simplemente a narrar una historia, sino que, al principio, antes de empezar a contar, realiza una pequeña presentación de lo que va a narrar: "Como un jugador socarrón y desinteresado, arrojaba imágenes, frases, escenarios inconexos. No respetaba el orden

${ }^{2}$ Las futuras referencias a la novela pertenecerán a Sacheri (2016), por lo que tan solo se indicarán entre paréntesis las páginas correspondientes. 
cronológico ni causal de los sucesos. No. Disparaba personajes, climas, hechos trascendentes, detalles, metáforas que nadie entendía, en una enumeración que parecía caótica» (12).

En otras palabras, Lombardero, antes de comenzar a narrar una historia, proporcionaba su tráiler. Los tráileres citan directamente ciertas partes de la película, creando una especie de "ventana» para atraer al espectador y dando lugar a un discurso hiperbólico que será, más tarde, desarrollado en la película (Kernan, 2004). Al igual que Lombardero, los tráileres arrojan imágenes, aparentemente inconexas, sin respetar el orden cronológico de la película (pues puede aparecer, al comienzo del tráiler, una imagen que corresponda al final del film), generando de este modo expectación y curiosidad en el auditorio. Por lo tanto, encontramos que en la figura de Lombardero se reúnen, al mismo tiempo, las cualidades del cinematógrafo y del creador de tráileres. No es de extrañar, en este sentido, que se le califique como «el único capaz de contar esta historia» (14) pues tan solo él disponía de las claves para contarla (claves que, se deduce, serían cinematográficas). De este modo, el narrador se pone en la piel de Lombardero, y nos cuenta cuáles serían los elementos que el cuentacuentos citaría antes de comenzar la historia, las imágenes y escenarios que arrojaría a modo de tráiler:

Diría que en ella hay un villano, un accidente de autos y un gerente de banco que huye pero termina alcanzado por la muerte. Un tipo que sumerge una topadora en la parte más profunda de la laguna y un muchacho que escapa para siempre. Una chica enamorada, unos cables eléctricos enterrados a lo largo de kilómetros y un hombre que llora porque sabe que jamás será feliz. Un albañil rencoroso a punto de morir y una estación de servicio en el empalme de una ruta (14).

Los puntos de la historia que adelanta desvelan partes fundamentales de la trama y podrían considerarse como spoilers, pues adelantan información primordial que, al revelarse más tarde, causará sorpresa en el lector. Sin embargo, para quien se aventure en su primera lectura de la novela, estos elementos, dispuestos de forma inconexa, no anticiparán nada, ya que, como ocurre con los tráileres, están faltos de contexto, son unidades simbólicas que tan solo podremos comprender una vez hayamos disfrutado de la narración completa. La función de ambos, por tanto, será la de suscitar la intriga, acudir a la emoción para que la historia cobre interés para el espectador.

Lombardero, una vez terminada su enumeración, anunciará el posible título que podría llevar la historia, La noche de la Usina. El prólogo terminará, sin embargo, en el momento en el que Lombardero, teniendo en cuenta su habitual técnica, habría comenzado a narrar la historia, dando paso así al Primer acto, y sugiriendo de esta forma que la novela no es sino la narración del propio cuentacuentos.

\section{Relaciones con la técnica de escritura del guion}

Como señalamos anteriormente, la experiencia de Sacheri como guionista se inició con la adaptación de su novela La pregunta de sus ojos en la película El secreto de sus ojos (2009) y continúa en la actualidad, pues ha participado como guionista en la adaptación de La noche de la Usina, bajo el título de La odisea de los giles (2019). A la hora de preguntarnos qué es un guion nos encontramos con que existen distintas definiciones y formas de realizarlo según cada guionista. Por lo general, los críticos coinciden en que el guion se trataría de un paso previo a la forma final, es decir, el producto audiovisual, y sus características estarán supeditadas a mostrar de forma clara 
la estructura y contenidos del film. En este sentido, aunque ambos pertenezcan al ámbito narrativo, las diferencias con la novela son claras, pues el guion no funciona por sí mismo como creación literaria, sino que se trata de una fase previa al producto cinematográfico final. El propio Sacheri, en una entrevista con la Radio Nacional de Colombia, marcará la diferencia fundamental entre la escritura de guion y de novela:

Uno, cuando escribe un guion, la palabra solo la usa para acciones y diálogos. En un libro, la palabra es una sola herramienta, pero nos conduce a un montón de utilidades posibles y a tiempos y velocidades totalmente diferentes, mientras que en el cine está subordinada la palabra a esa cosa de acciones y diálogos y tal vez lo difícil es cómo usar la palabra para profundizar cosas que en realidad profundizarán luego los actores, las locaciones, la cámara, la fotografía, la música... Pero, digamos, la palabra ahí tiene un lugar mucho más humilde (Radio Nacional de Colombia, 2017). ${ }^{3}$

Como el autor explica, la escritura de guion y novela perseguirán finalidades distintas y estarán, además, influidas (en el caso del cine) por la presencia de otras formas de comunicación (fotografía, música, etcétera). Sin embargo, en ambas encontramos un punto en común que permitirá el trasvase de influencias de un medio a otro: la palabra. Ambas formas de comunicar encontrarán en la palabra su materia prima, convirtiéndose en un elemento indispensable en el mundo del cine, ya sea en forma de diálogo o como medio para apuntar las características visuales de la futura escena o acciones que se desarrollarán en ella, por lo que no es descabellado pensar que esa visualidad de la narración del guion pueda haber sido transportada, en algunos puntos, a la novela. De hecho, el propio Sacheri ha destacado en varias ocasiones lo visual de su escritura, explicando que

Yo creo que mi manera de escribir la pienso, la pienso, la pienso y la pienso; la veo, la veo, la veo [...] Es como que mientras estoy pensando el libro, [...] lo estoy viendo. Calculo que tengo una manera muy visual de pensar el libro que redunda en que al momento de escribirlo queda una manera también bastante visual de escribirlo... Y en una de esas eso facilita que un director de cine lee el libro y capaz que tiene como ese entusiasmo adicional de decir «che, pará que esto está medio... medio hecho ya, medio avanzado en esa dirección» (Cadena 3, 2019). ${ }^{4}$

Nuestro objetivo, por tanto, será demostrar que, en algunas partes de la novela, es posible hallar pasajes descritos de manera muy visual que nos llevan a pensar en una posible influencia del estilo de escritura asociado al guion, haya sido esta técnica aplicada por el autor de manera consciente o inconsciente. No se tratará de justificar la novela en cuanto guion cinematográfico, sino de mostrar cómo el aprendizaje de las técnicas del guion ha podido influir en la narración de algunos capítulos.

Como hemos mencionado anteriormente, el resultado de lo escrito en el guion está destinado a convertirse en un producto audiovisual, es decir, que, como explican Aranda y De Felipe (2012: 18), «[...] un guion ha de ser en primer lugar una lectura que cree visualmente en la mente del lector la película que pretendemos realizar». Primará, por tanto, la descripción de las acciones en forma de claras impresiones visuales, que permitirán al lector formar en su mente una imagen de lo ocurrido. Siguiendo esta técnica, es posible encontrar en la novela pasajes que describen el movimiento de los

${ }^{3}$ Transcripción de la entrevista radiofónica.

4 Transcripción de la entrevista radiofónica. 
personajes de manera clara y concisa, transmitiendo de forma detallada el dinamismo de la escena:

Perlassi se pone en pie y con un manotazo furioso revolea el termo, que se estrella contra la pared del parador con un estruendo de vidrios rotos. Fontana lo mide desde su lugar. Belaúnde los mira desde su silla. Finalmente también se incorpora y camina hacia su auto. Fontana lo sigue. El Citroën no enciende al primer intento. Recién en el tercero, y después de algunas toses, el motor se pone en marcha. La caja de cambios cruje cuando Belaúnde pone la marcha atrás. El auto se aleja hacia la ruta. Es casi de noche. Perlassi levanta el mate de calabaza que ha quedado solo sobre la mesa y camina hacia el edificio (96-97).

El pasaje que nos sirve como ejemplo se corresponde con el final del primer capítulo del segundo acto. Tras la muerte de Silvia, Belaúnde y Fontana deciden visitar a Perlassi y contarle lo que han descubierto: que fue Manzi quien les robó el dinero y lo escondió en una bóveda. Ante la actitud indiferente de Perlassi — todavía en duelo-, Fontana estalla y le reprocha su negatividad, lo que provoca la acción que se ve reflejada en este último párrafo. Si antes hemos afirmado que el guion es un producto creado para ser visto y oído, es interesante destacar que en este pasaje podemos encontrar referencias a los efectos sonoros que las acciones de los personajes producen. Tanto el termo, que se estrella en la pared «con un estruendo de vidrios rotos» como las toses de Belaúnde o el ruido de la caja de cambios recrean en la mente del lector una escena completa, evocando los sentidos de la vista y el oído. Predominan, además, las frases cortas y de una o dos acciones, que narran de manera concreta la reacción de cada personaje al estallido inicial que supone el manotazo de Perlassi. En la referencia a que «Es casi de noche» encontramos también una marca temporal que nos indica el transcurso del tiempo desde que Belaúnde y Fontana llegaron, pudiendo considerarse incluso como una indicación directa a la iluminación que ha de tener la escena.

Según explica Alberto Mario Perona (2010), las referencias al clima, la iluminación, los personajes y el vestuario de los mismos se corresponden con el guion literario, mientras que las acotaciones técnicas (el tipo de plano, el encuadre...) se incluyen en el guion técnico, pues el literario prescindirá de ellas (aunque puede incluir, de manera indirecta, referencias al enfoque para mostrar así la visión del guionista durante el planteamiento de la escena). Se podría argumentar, por tanto, que en el párrafo encontramos, indirectamente, reflejada la visión del autor respecto al enfoque que debería tomar la cámara, pues el foco se mueve de Perlassi a Fontana, de este a Belaúnde, que se incorpora, y de nuevo a Fontana, siguiéndolo hasta el coche de Belaúnde, y de nuevo de vuelta hasta Perlassi, como si de una cámara cinematográfica se tratase. Otra característica que marcará la narración del guion literario será la utilización de verbos siempre en tiempo presente y en tercera persona (Mario Perona, 2010), pues estos harán referencia a las acciones que están sucediendo de forma inmediata. Este tiempo verbal predominará a lo largo de toda la novela. Junto a él, el diálogo, que utiliza un registro coloquial y se enmarca en la variedad del español de Argentina, irá construyendo de forma precisa las escenas que constituyen cada capítulo. Cabe destacar, además, el uso predominante de un diálogo desnudo, con escasas aclaraciones. En el capítulo cuatro del segundo acto podemos observar un ejemplo de esto último: 
Fontana se sienta, resoplando exhausto como si acabase efectivamente de asesinar a Manzi. Exhausto y feliz. Perlassi lo mira. Sonríe y niega.

-No te creo, Fontana.

- ¿Ah, no? Ya vas a ver.

-No. No sos capaz.

-Vamos a ver si no soy capaz.

-No, no sos. Porque sos un buen tipo.

- Pero Manzi es un hijo de puta.

—Es verdad. Pero eso lo sabemos vos y yo, además.

- ¿Cómo, vos y yo?

- Claro. Él no sabe.

-No puede no saberlo (108-109).

El diálogo se desarrolla entre Fontana y Perlassi; sin embargo, la alternancia de respuestas entre uno y otro hace que, desde la primera intervención donde se nombra a Fontana (y, por tanto, el que habla es Perlassi), ya no haga falta aclarar quién pronuncia cada parlamento. El rápido intercambio entre uno y otro en forma de frases cortas, concretas, coloquiales, crea una escena dinámica y de un vívido realismo, que el lector es capaz de interpretar en su mente. En la obra encontramos, por tanto, características prototípicas de la escritura de guion, sin embargo, esto no quiere decir que esté construida utilizando esta forma. Los guionistas suelen coincidir en que los guiones han de ser concretos y prescindir de cualquier tipo de información lírica o no necesaria. Como pieza narrativa, la novela (aunque en ningún momento pecará de lirismo) integrará ambas influencias y se valdrá de ellas para crear una historia con una importante vertiente visual.

\section{La noche de la Usina como revisión de géneros cinematográficos}

El jurado del XIX Premio Alfaguara de novela, concedido en 2016 a Eduardo Sacheri, describió su obra como «una novela coral, ágil y emotiva, con muchos ingredientes de lo mejor del thriller y el western». Aunque es cierto que La noche de la Usina bebe de influencias ficcionales variadas y diversas, ${ }^{5}$ la presencia de la cinematográfica será fundamental tanto en la construcción de la trama como en la de los personajes y espacios. Cabe destacar, además, que los dos géneros que el jurado atribuyó como principales influencias hayan sido el thriller y el western, comúnmente categorizados como «géneros canónicos» o «mayores» (Huerta Floriano, 2005), fundamentales en la cinematografía norteamericana.

El western

El western como género cinematográfico nace en Estados Unidos a principios del siglo XX, junto a las primeras producciones fílmicas. La mayoría de los críticos están de acuerdo en señalar The Great Train Robbery (1903) como la primera producción categorizada como western (Lusted, 2014). André Bazin explica en «The Western: or the American Film par Excellence» que el western nace de la tradición folclórica y se construye unido al mito. En este género se vuelve fácil encontrar un aparente maniqueísmo en los personajes, «which sets the forces of evil over against the

5 No solo encontramos en sus páginas referencias cinematográficas, sino también literarias: Borges o Jean Lartéguy, entre otros autores, conformarán el canon personal de los vecinos de O’Connor. 
knights of the true cause» (2004: 146), pues, de manera recurrente, el indio, incapaz de adaptarse al orden social, luchará contra el cristiano blanco, digno conquistador del nuevo mundo. Así, se desarrollará la faceta épica que caracteriza el periodo histórico de la conquista del Oeste, y que Bazin (2004) compara con el protagonismo de la Revolución Soviética en el cine histórico ruso. A pesar de este maniqueísmo inicial, en reiteradas ocasiones encontraremos en el western pasajes que incitan a la reflexión política, cuestionando las relaciones entre moral y justicia: «[...] epic becomes tragedy, on the appearance of the first conflict between the transcendence of social justice and the individual character of moral justice, between the categorical imperative of the law which guarantees the order of the future city, and the no less unshakeable order of the individual conscience» (Bazin, 2004: 148).

Aparecerán, de este modo, contradicciones inevitables, pues en ocasiones será imposible constatar una diferencia moral entre el sheriff, que representa la justicia, y el bandido al que apresa. Curiosamente, sin embargo, Bazin (2004) dirá que los mejores westerns son aquellos que personalmente considera «novelísticos», caracterizados por, sin salirse de los temas tradicionales, enriquecer la historia con personajes originales, individuales y con gran profundidad psicológica, tal y como se esperaría del héroe de una novela, lo que nos hace reflexionar de nuevo sobre los intercambios constantes entre cine y literatura.

En La noche de la Usina encontraremos algunos de los rasgos principales del western trasladados al contexto cultural argentino de principios del siglo XXI. En ambos casos, el detonante de la acción será un acontecimiento histórico, pues si bien en el western se producía una vuelta al tiempo de la conquista del Oeste, naciendo el conflicto del enfrentamiento entre indios y blancos, en nuestra novela la acción tendrá lugar como consecuencia de la crisis del corralito que asoló la nación argentina en 2001. Sin embargo, como los westerns novelísticos de los que hablaba Bazin, la novela supera el maniqueísmo prototípico del género cinematográfico: la división completamente estanca entre «los buenos» y «los malos» se vuelve más laxa, pues a través de la narración desde el punto de vista de Manzi (el supuesto villano) se ahonda en la psicología del personaje, acercándolo al lector y ayudándole a comprender sus motivos. Aparecen, además, en la novela algunas reflexiones por parte del grupo de Perlassi y compañía en las que se cuestiona la naturaleza del comportamiento del empresario, como los siguientes fragmentos, que pertenecen al capítulo octavo del tercer acto:

— ¿Sabés cuál es mi duda?

Perlassi habla mientras hunde la pala. Evitan que la tierra que extraen se esparza demasiado.

- Si los tipos como Manzi piensan que los hijos de puta son ellos o son los demás. Los que le hacen la contra.

-No te entiendo.

- Claro. Manzi nos cagó. Eso lo sabemos. Pero Manzi: ¿piensa que nos cagó? ¿O piensa que hizo un negocio y que, de haber podido, nosotros habríamos hecho lo mismo?

- Son las diez menos uno - informa Perlassi.

Fontana asiente.

-En eso tenés razón — dice.

— ¿En qué son las diez menos uno?

- No. En que casi todos los hijos de puta se creen que no son hijos de puta. 
—ué bueno, ¿no?

- ¿Qué cosa?

-Eso de ser un hijo de puta y creerse buena gente. Hacés lo que querés. Cagás a medio mundo y dormís como un angelito.

— ¿Vos decís? ¿Dormirá como un angelito? (213-214).

El ahondamiento en la psicología del personaje nos demuestra que, lejos de ser plano, se buscan los motivos que lo han podido llevar a actuar de esa forma. De igual manera, también se descubren tonos de grises en el grupo de «los buenos» (los cuales, al fin y al cabo, serán criminales), sobre todo cuando se desvela, al final del cuarto acto, que Hernán se ha fugado con el dinero que planeaban devolver a Manzi. Esta reflexión entre moral y justicia nos lleva ante la posibilidad de considerar a Perlassi como el bandido honrado, pues si bien comete un acto delictivo, este se encuadra dentro de la moral de la justicia individual, queriendo, en todo momento, recuperar tan solo lo que les fue robado (aunque al final tuviesen que desvalijar la bóveda por completo). A propósito de esto, Sacheri explica que «más que venganza, se trata de una revancha. Creo que la venganza es, simplemente, infligirle dolor a quien hizo daño. La revancha, en cambio, te enaltece; es sacar la cabeza del fondo del agua» (Blanc, 2016). No se trata de héroes llevando a cabo una gran hazaña, sino de gente común, corriente, que intenta sobrevivir y prosperar ante la dificultad que le impone su contexto social y la repercusión de las acciones de los demás.

Al igual que en el western, la novela se desarrolla principalmente en el campo. No solo aparecen referencias a la naturaleza cuando se narran las escenas que se desarrollan dentro del terreno de Manzi, sino que las descripciones de las principales localizaciones sugieren espacios abiertos, encuadrados en ambientes naturales y con escasa presencia humana. De este modo, ya desde el primer capítulo se establece una diferencia entre O'Connor y Villegas, situando al primero como un pueblo sin apenas avances tecnológicos o recursos, asociado al estatismo y a la escasa afluencia de gente o negocios, y al segundo como la ciudad, ligada al dinero y a los empresarios. También en las descripciones que rodean al paisaje de la estación de servicio de Perlassi, que en ocasiones se retrata como un paraje sosegado y en calma («En el silencio del campo y de la noche crece un zumbido agudo y metálico», 50), se hace referencia al entorno natural que la rodea. Cabría destacar, además, el guiño directo que se realiza al género en el capítulo doce del segundo acto, donde, para evitar que Manzi descubra la primera incursión del grupo, Perlassi introduce una vaca en el recinto vallado, con la intención de hacer creer al empresario que ha sido esta y no ellos quienes han arrancado el poste. De esta forma, durante el capítulo se narra, de manera cómica, el intento fallido del grupo de enlazar una vaca, al más puro estilo cowboy, que concluye con los hermanos López agarrando a un ternero e introduciéndolo en el cercado para que la madre, enfurecida, vaya a buscarlo.

El thriller

Existe cierto consenso a la hora de considerar que el género del thriller engloba tanto a las películas policíacas como las de espionaje, que a su vez se solapan con las de aventura y las de guerra (Pinel, 2009). Puede entenderse también como sinónimo de cine negro, aunque las especificaciones varían dependiendo del autor. Suele tratar asuntos criminales, apelando de manera directa al suspense, y su apogeo lo encontraríamos a mitad de la década de los cuarenta. Álvaro A. Fernández explica que 
en el thriller «[...] se rompe el equilibrio del universo cotidiano del protagonista (mundo generalmente moderno, urbano y globalizado), gracias a un acontecimiento transformador que lo convierte en víctima y lo inserta en un espacio laberíntico» (2014: 52). Según esta afirmación, se podría argumentar que Sacheri utiliza la estafa del corralito (reforzada por la muerte de Silvia, en el caso de Perlassi) como acontecimiento transformador de la vida de los personajes.

En la novela no solo encontraremos relaciones con el thriller en el desarrollo de la trama, sino que los propios personajes pensarán en sus acciones en términos cinematográficos, relacionándolas, principalmente, con el cine de espías y el de temática bélica. Por una parte, las estrategias que llevan a cabo durante toda la novela para que Manzi no se percate de que están intentando robarle imitan la planificación de los mejores espías. Un ejemplo de esto lo encontramos en el hecho de que, en su primera incursión al terreno donde se encuentra la bóveda, Perlassi les hace a todos utilizar mocasines, pues así Manzi no podrá diferenciar las huellas de las suyas propias (161). De igual forma, los hermanos López se convierten en espías improvisados cuando se hacen pasar, en el capítulo veinticuatro del tercer acto, por funcionarios de la Cooperativa Eléctrica de O'Connor para que Manzi no sospeche que son ellos los que están alterando el cableado de la bóveda. El método del disfraz es uno de los grandes identificativos del cine de espías, pues sus protagonistas se hacen pasar por quien no son para engañar a sus adversarios. Así, los propios personajes de la novela comentan la escena relacionándola con la tradición cinematográfica:

— Ja -Perlassi sonríe- El otro son los López. No sabés el agrande que tienen. Se pasaron la tarde acá, tomando cerveza y relatándome con pelos y señales la charla con Manzi. A Eladio lo escuchás y, según él, es James Bond.

Rodrigo, casi a su pesar, suelta una risita.

—Encima Belaúnde les daba manija. No sabés. Les decía que trabajar como «agentes infiltrados» no es para cualquiera. Y estos dos no pasaban por las puertas, te imaginás.

-Ahora los López son del Mosad.

—Del Mosad, la KGB, alguno de esos (267).

Cabe destacar la utilización del lenguaje aprendido del cine para planificar el golpe. Los López pasan a ser «agentes infiltrados», el plan de Perlassi es bautizado como «Plan Audrey Hepburn» (aunque, en ocasiones, se refieren a él mediante «el golpe») y los vecinos se autodenominan «grupo comando». En lo relativo al lenguaje bélico, se introduce en la novela a través del personaje de Fontana, quien lo aprende gracias al cine de guerra. El propio Perlassi lo señala cuando, al verlo utilizar unos binoculares, comenta: «Tenés muchas películas de guerra encima, vos. Demasiado Rommel, demasiado Patton» (125). Es, por lo tanto, Fontana el que, cuando hablan de la necesidad de que alguien esté cerca de Manzi para poder espiarlo, sugiere el término «quintacolumnista», y, más tarde, añade que Rodrigo se ha «introducido en el campo enemigo» y que debe «volver a infiltrarse» para «recabar cualquier detalle digno de consideración» (198). En relación con esto, Carmen Peña-Ardid explica que «El cine ha sido un gran creador de estereotipos, comportamientos e incluso modalidades del habla en los que, a veces, se apoyará el escritor, bien por un principio de economía semántica, bien para instaurar determinadas complicidades con unos lectores dotados también de una "competencia espectatorial"» (1999: 100).

Todos estos préstamos tomados del cine, al igual que las referencias a situaciones tradicionales del thriller o el western, dan lugar a lo que Umberto Eco 
(1993) denomina «cuadros intertextuales», es decir, situaciones prototípicas del cine que el lector reconoce como parte de su acervo cultural. En este sentido, es gracias a la «competencia espectatorial» sugerida por Peña-Ardid (1999) como el público entiende las distintas alusiones en la obra. Además, el hecho de que se trate de menciones a los grandes géneros canónicos facilita su comprensión, pues estos, al tratarse de los pilares del cine, han nutrido a una amplia tradición de géneros menores, instaurándose en las bases de la cultura audiovisual y siendo, de esta manera, improbable que pasen inadvertidos.

La relación de los personajes con el mundo bélico y del espionaje es vista, sin embargo, con una mirada paródica por parte de Rodrigo. Él representa la visión más realista, que nos recuerda que los protagonistas de la novela no son James Bond sino unos vecinos de un pequeño pueblo rural. Como ejemplo, encontramos la conversación que mantiene con Hernán, en el capítulo dieciocho del tercer acto:

—Sí — concede Rodrigo - Pero no me puedo sacar de la cabeza que somos... ¿Vos viste lo que somos?

Hernán se sonríe y asiente. Rodrigo, que tiene las piernas sobre la guantera del auto para desentumecerlas, empieza a enumerar contando con los dedos de la mano izquierda.

-Fontana. Belaúnde. Los López. Vos.

—Y vos! ¿Qué te creés? Tu viejo. Mi viejo...

- ¡Y Medina! ¡Medina! ¡No te olvides, te pido por favor, que estamos intentando dar el golpe del siglo con el viejo Medina! (245).

También Hernán pone en duda la capacidad del grupo para llevar a cabo el plan cuando, en la primera incursión al terreno de Manzi, los compare con los protagonistas de una película y se dé cuenta de que la realidad es muy distinta:

Hernán piensa que el «grupo comando», así como está, desperdigado por el campo de Manzi, parece salido de una de esas películas en las que algunos rastreadores buscan a un fugitivo en medio de los pastizales. Falta el fugitivo, claro. Y faltan los sabuesos. Y faltan otros veinte rastreadores para que la búsqueda parezca algo más o menos serio, porque el grupo real, tal como se lo ve, seis tipos un poco a la deriva, como quien busca un llavero que se le cayó por un agujero del bolsillo, no da la sensación de que esté capacitado para encontrar absolutamente nada (138).

Sin embargo, mientras que Hernán, aunque dudoso, se apunta a la operación desde un principio, Rodrigo se mantiene en todo momento reticente a la idea: «Porque no sabe mantener plantas, porque no es un espía, porque no le parece bien todo ese plan de energúmenos que están llevando adelante» (121). Aun así, acaba aceptando hacerse pasar por jardinero para infiltrarse en la oficina de Manzi, y poco a poco su implicación será mayor. En gran parte, esto se debe a la presencia de Florencia, la secretaria del empresario, de la que Rodrigo queda prendado al instante. Si atendemos a N. Simsolo, quien afirma que «[...] la motivación del comportamiento de sus personajes [del cine negro] suele ser el deseo sexual y los dramas se desatan a causa de una mujer de sensualidad devoradora o dotada de una belleza excepcional» (2009: 261), podemos encontrar cierto paralelismo con la actuación de Rodrigo, cuya motivación para seguir acudiendo a la oficina de Manzi y, por tanto, seguir adelante con el plan se debe a su interés en Florencia. 


\section{CONCLUSIONES}

Como hemos visto en los distintos apartados de este artículo, el cine influye de manera decisiva en la construcción de la novela La noche de la Usina. Por una parte, se ha demostrado la existencia de puntos en común entre el prólogo de la obra narrativa y el tráiler cinematográfico. Ambos funcionan como paratextos - presentan el producto a un público lector o audiencia-, pero no solo eso, sino que además se asemejan en su configuración formal, pues en el prólogo de la novela se incluyen de manera inconexa diversas imágenes y acontecimientos futuros que, por sí solos, no revelan información esencial del libro, pero que cumplen la función de causar intriga y de apelar a lo emocional para originar la curiosidad en el lector. En un sentido más amplio, hemos constatado en este artículo el importante nexo entre palabra e imagen que se forja en la configuración narrativa de la novela. El propio autor destaca su tendencia a imaginar de forma visual, lo que, sumado a su experiencia como guionista, nos lleva a argumentar que existen lazos de influencia entre el estilo de esta novela y la escritura del guion, cuyas características esenciales se ven reflejadas en distintos pasajes de la obra. Más allá del análisis formal, nuestra investigación ha tratado la manera en que dos de los géneros cinematográficos canónicos como son el thriller y el western aparecen reflejados en la construcción de la trama, los espacios y los personajes de La noche de la Usina. Por una parte, el western aparece reflejado - además de en el propio espacio donde se desarrolla la trama - en las dicotomías y reflexiones morales que la propia historia plantea; sin embargo, supera el maniqueísmo propio del género y da lugar a un producto narrativo original y sólido. En el caso del thriller, su influencia se destaca sobre todo en la construcción de los personajes, grandes amantes del cine bélico y de espías. En su propia concepción de la realidad (ven su estrategia como sacada de una película) y en sus motivaciones se pueden distinguir los temas y tópicos prototípicos del género, que se ve parodiado gracias al personaje de Rodrigo, quien, atado a la realidad, les recuerda incesantemente que no son más que un grupo de vecinos de un pequeño pueblo argentino.

\section{OBRAS CITADAS}

Aranda, Daniel y Fernando De Felipe, (2012), Guion audiovisual, Barcelona, Editorial UOC.

Bazin, André (2004), What is cinema?: Volume II, trad. Hugh Gray, California, University of California Press.

Blanc, Natalia (1 de octubre de 2010), «El regreso de Campanella-Sacheri», La Nación, $<$ https://www.lanacion.com.ar/cultura/el-regreso-de-campanella-sacheri-nid1309604>.

Blanc, Natalia (6 de abril de 2016), «Eduardo Sacheri: un premio hecho realidad», La Nación, $<$ https://www.lanacion.com.ar/cultura/eduardo-sacheri-un-premio-hecho-realidadnid1886550>.

Cadena 3 (13 de noviembre de 2019), «Eduardo Sacheri: "Tengo una manera muy visual de pensar"» [extracto de entrevista], <https://www.cadena3.com/noticia/juntos/eduardosacheri-tengo-una-manera-muy-visual-de-pensar_245997>.

Carmona, Ramón (2010), Cómo se comenta un texto filmico, Madrid, Cátedra.

Eco, Umberto (1993), Lector in fabula: La cooperación interpretativa en el texto narrativo, trad. Ricardo Pochtar, Barcelona, Lumen. 
Fernández, Álvaro (2014), «Nuevas matrices en el thriller latinoamericano», en Nancy Berthier y Antonia del Rey-Reguillo (eds.), Cine Iberoamericano Contemporáneo y Géneros Cinematográficos, Valencia, Tirant Humanidades, pp. 51-69.

Fernández Fernández, Luis Miguel (1993), «Literatura y cine (desde esta ladera: la literatura comparada)», Signa: revista de la Asociación Española de Semiótica, 2, pp. 37-56.

Genette, Gérard (1989), Palimpsestos: La literatura en segundo grado, trad. Celia Fernández Prieto, Madrid, Taurus.

Genette, Gérard (2001), Umbrales, trad. Susana Lage, Argentina, Siglo Veintiuno Editores.

Huerta Floriano, Miguel Ángel (2005), Los géneros cinematográficos: usos en el cine español (1994-1999), Salamanca, Universidad Pontificia de Salamanca.

Kernan, Lisa (2004), Coming Attractions: Reading American Movie Trailers, Austin, University of Texas Press.

Lusted, David (2014), The Western, Londres, Routledge.

Mario Perona, Alberto (2010), El aprendizaje del guion audiovisual: Fundamentos, metodología y técnicas, Argentina, Editorial Brujas.

Miranda, Carolina (2018), «Crime and Punishment: From Victims to Avengers in Eduardo Sacheri's La noche de la Usina», en Shalisa M. Collins, Renee W. Craig-Odders y Marcella L. Paul (eds.), Violence and Victimhood in Hispanic Crime Fiction: Essays on Contemporary Works, North Carolina, McFarland \& Company Inc, pp. 108-125.

Peña-Ardid, Carmen (1996), «Rupturas de la mímesis (nuevas reflexiones sobre las "influencias" del cine en la novela)», Moenia, 2, pp. 225-252.

Peña-Ardid, Carmen (1999), Literatura y cine, Madrid, Cátedra.

Pérez Bowie, José Antonio (2008), «La adaptación cinematográfica a la luz de algunas aportaciones teóricas recientes», Signa: revista de la Asociación Española de Semiótica, 13, pp. 276-300.

Pichois, Claude y André Rousseau (1969), La literatura comparada, Madrid, Gredos.

Pinel, Vincent (2009), Los géneros cinematográficos: géneros, escuelas, movimientos y corrientes en el cine, trad. Caterine Berthelot, Barcelona, Ediciones Robinbook.

Radio Nacional de Colombia (30 de agosto de 2017), «Sacheri será el guionista de la película La Noche de la Usina» [extracto de entrevista], $<$ https://www.radionacional.co/noticia/literatura/eduardo-sacheri-confirma-que-lanoche-de-la-usina-ira-al-cine $>$.

Regosa, Mauricio (2003), Per un'analisi del trailer cinematografico, Florencia, Alinea Editrice.

Sacheri, Eduardo (2016), La noche de la Usina, Madrid, Alfaguara.

Sánchez Noriega, José Luis (2000), De la literatura al cine: teoría y análisis de la adaptación, Barcelona, Paidós Ibérica.

Schmeling, Manfred (1984), «Introducción: Literatura General y Comparada. Aspectos de una metodología comparatista», en Manfred Schmeling (ed.), Teoría y praxis de la literatura comparada, trad. Ignacio Torres Corredor, Barcelona, Alfa, pp. 5-8.

Schmitt-von Mühlenfels, Franz (1984), «La literatura y las otras artes», en Manfred Schmeling (ed.), Teoría y praxis de la literatura comparada, trad. Ignacio Torres Corredor, Barcelona, Alfa, pp. 169-193.

Simsolo, Noël (2009), El cine negro, trad. Alicia Martorell Linares, Madrid, Alianza Editorial.

Urrutia, Jorge (1975), La literatura española y el cine (bases para un estudio) [Tesis doctoral], Madrid, Universidad Complutense de Madrid.

Urrutia, Jorge (1984), Imago litterae: cine, literatura, Sevilla, Alfar.

Urrutia, Jorge (1999), «Leer, conocer, filmar, decir», en Carmen Peña-Ardid (coord.), Encuentros sobre literatura y cine, Teruel, Instituto de Estudios Turolenses/Caja de Ahorros de la Inmaculada, pp. 21-36.

Villa, Catalina (22 de enero de 2013), «El escritor argentino Eduardo Sacheri revela el "secreto" de sus letras», El País.com., < $<$ https://www.elpais.com.co/elpais/cultura/noticias/escritorargentino-eduardo-sacheri-revela-secreto-sus-letras $>$.

Weisstein, Ulrich (1975), Introducción a la literatura comparada, Barcelona, Planeta. 
Wellek, René (1968), Conceptos de crítica literaria, Venezuela, Universidad Central de Venezuela.

Recibido: 25/05/2020

Aceptado: 08/07/2020 